\title{
Integração de Dispositivos Críticos de Segurança em uma Industria Esmagadora de Soja
}

\author{
Jordame A. Silva, Dárley D. de Almeida \\ Departamento de Ciência da Computação Universidade do Estado do Mato Grosso \\ (UNEMAT) - Alto Araguaia, MT - Brasil \\ \{jordamea@gmail.com, darleydalmeida@gmail.com
}

\begin{abstract}
Management Process Safety (PSM) is a growing issue. The aim of this paper is to present the importance of using Safety Critical Devices in industries, making a brief introduction about processes in food industries and the benefits of using computing through devices dedicated to process safety monitoring.

Resumo: Gerenciamento Segurança de Processo (PSM) é um assunto que vem crescendo em importância. $O$ objetivo deste trabalho é apresentar a importância da utilização de Dispositivos Críticos de Segurança em indústrias, realizando uma breve introdução sobre processos em indústrias alimentícias e os benefícios de utilizar a computação através de dispositivos dedicados à monitorização da segurança de processo.
\end{abstract}

\section{Introdução}

Como toda indústria, a fábrica esmagadora de soja também depende de um sistema para otimização de seu processo produtivo que auxilie nas tomadas de decisões operacionais e gerenciais. Quanto maior a indústria, mais complexo se torna o processo, aumentando assim o risco de acidentes devido condições de trabalhos dos equipamentos.

A Fábrica esmagadora de soja é um segmento industrial que extrai do grão de soja óleo vegetal e a massa do grão em farelo. O produto processado movimenta uma grande parcela do agronegócio mundial impactando diretamente na economia do pais (SILVA, LIMA, BATISTA 2011). O processo de uma esmagadora de soja, assim como em outras grandes indústrias, passa por dificuldade de controle seguro de seu processo. Devido a demanda de produto o equipamento tem uma carga horaria de trabalho muito alta gerando risco frequente de acidentes com perdas significativas, para pessoas e para o processo produtivo.

O monitoramento e atuação nos equipamentos em caso de um potencial acidente deve ocorrer através de dispositivos dedicados somente para essa finalidade, sendo esses dispositivos denominados de CSD (Critical Security Devices - Dispositivos Críticos de segurança). Para que possa se ter controle desses dispositivos também e necessário a integração dos dados coletados nos equipamentos a um sistema de supervisório.

O objetivo deste projeto é, primeiramente, demonstrar a importância de gerenciamento de segurança de processos industriais, para, a partir disso, desenvolver um aplicativo de operação remota para o CLP, que permita monitorar os sensores online de qualquer lugar 


\section{Desenvolvimento}

Os sensores de temperatura convertem a grandeza física temperatura em um sinal elétrico. [MARTINS et al, 2014], assim, ao colocar um sensor em um equipamento para monitorar sua temperatura enviar o sinal elétrico para o CLP (Controlador Lógico Programável ou PLC do inglês, Programmable Logic Controller) são definidos os limites aceitáveis de condições de trabalho para cada equipamento, sendo que ao atingir os limites o CLP recebe o sinal do sensor que está instalado no campo e atua parando o equipamento evitando assim o risco de um acidente na indústria, porém reduzindo o processo produtivo.

Demonstrada a importância de gerenciamento de segurança de processos industriais, está sendo realizado o levantamento e análise de requisitos para embasar o desenvolvimento de um aplicativo móvel que permita monitorar os sensores remotamente via Internet, agregando mais comodidade e por que não, segurança ao monitoramento das variáveis do processo, com estatísticas antes de ocorrer a falha no equipamento e ser necessário a atuação do controlador interrompendo o processo produtivo. O processo de levantamento de requisitos em questão está sendo levantado através de entrevistas com os funcionários que operam e gerenciam o CLP, e também através do estudo dos manuais de operação do sistema, para identificar tanto as informações mais relevantes para um monitoramento remoto quanto para identificar como realizar a leitura e comunicação do aplicativo com o sistema físico.

\section{Considerações Finais}

Espera-se que após a realização de testes em bancada com um sensor de temperatura PT 100 atuando de modo secundário após a falha do sensor principal, será obtido com mais precisão a redução do risco de processo após a instalação de um CSD e o monitoramento remoto via aplicativo móvel que será desenvolvido.

Após a realização de pesquisas e estudos de PSM e outras técnicas de mapeamento de risco e produção total, será desenvolvido um aplicativo para monitoramento remoto de sensores de segurança de processo, para que o responsável pelo processo possa realizar alterações em variáveis antes que o controlador atue caso os sensores detectem alguma anomalia no equipamento monitorado. $\mathrm{O}$ referido aplicativo encontra-se em fase de levantamento e análise de requisitos, e em atividades futuras serão realizadas a modelagem, prototipagem, implementação e testes.

\section{Referências}

ANP. "http://www.anp.gov.br/images/Palestras/SOMAT2/1-Seguranca_de_processoCCPS.pdf". Setembro.

ABEPRO. “http://www.abepro.org.br/biblioteca/enegep2013_TN_STO_180_028_230 92.pdf'. Setembro.

Martins, A. B.; Souza, C. G.; Neves, J. A.; Silva, R. O.; Nogueira, S. C. Sistema De Controle Com CLP para secagem de roupa. Trabalho de Conclusão de Curso apresentado ao Instituto Federal de Educação, Ciência e Tecnologia de São Paulo Campus São José dos Campos, como requisito para obtenção do Título de Técnico em Automação Industrial. 2014. 
APEC. "http://www.apec.unesc.net/V EEC/sessoes tematicas/Economia\%20rural\% $20 \mathrm{e} \% 20$ agricultura $\% 20$ familiar/A $\% 20 \mathrm{IMPORT} \% \mathrm{C} 3 \% 82 \mathrm{NCIA} \% 20 \mathrm{DA} \% 20 \mathrm{SOJA} \% 20 \mathrm{P}$ ARA\%20O\%20AGRONEG\%C3\%93CIO\%20BRASILEIRO.pdf”. Setembro. 